\title{
Effect of Air Humidity on the Diffusion Rate of Migrating Corrosion Inhibitor in Mortars
}

\author{
Xiangyu Lu $^{1, *}$, Yunxia Guo ${ }^{1}$, Pei Zhang ${ }^{2}$, Chuanbo Zheng ${ }^{1}$ \\ ${ }^{1}$ School of Materials Science and Engineering, Jiangsu University of Science and Technology, \\ Zhenjiang 212003, Jiangsu, China \\ ${ }^{2}$ College of Chemistry and Food Science, Yulin Normal University, Yulin 537000, Guangxi, China \\ *E-mail: luxiangyu2013@163.com
}

doi: $10.20964 / 2017.08 .15$

Received: 5 April 2017 / Accepted: 31 May 2017 / Published: 12 July 2017

\begin{abstract}
The diffusion rate of a migrating corrosion inhibitor in mortars under dry air and humid air conditions was studied by electrochemical impedance spectroscopy. The results suggest that the impedance values of mortars increased with the concentration of the inhibitor. On the other hand, the impedances of the mortars maintained in the dry air are significant higher than the ones in the humid air condition. The fitting results show that the resistances of the concrete cover layer were obviously enhanced by the brushed corrosion inhibitor on the mortar surface. Meanwhile, the diffusion rates of the inhibitor in mortars also were accelerated by the high humidity of air.
\end{abstract}

Keywords: migrating corrosion inhibitor, electrochemical impedance spectroscopy, Warburg impedance, diffusion.

\section{FULL TEXT}

(C) 2017 The Authors. Published by ESG (www.electrochemsci.org). This article is an open access article distributed under the terms and conditions of the Creative Commons Attribution license (http://creativecommons.org/licenses/by/4.0/). 